\title{
Wheel tracking test (WTT) conducted under different standards. Study and correlation of test parameters and limits
}

\author{
F. Morea $\cdot$ R. Zerbino
}

Received: 6 March 2014 / Accepted: 23 October 2014

(C) RILEM 2015

\begin{abstract}
The wheel tracking test (WTT) is an important tool to define asphalt mixture rutting performance. In this study, the rutting behaviour in the WTT was compared under two different standards, BS 598-110 and EN 12697-22 small size device procedures. A significant number of mixtures were studied considering different volumetric characteristics, binder types and test temperatures. The relationship between calculated test parameters in both standards is discussed. Similar deformation rate responses in mixtures using both test methods were observed. A correlation between the calculated parameters rutting rate of BS 598-110 and wheel tracking slope (WTS) of EN 12697-22 was obtained. Possible WTS limits are discussed, considering previous experience in the WTT according to BS 598-110 and the relations obtained with the low shear viscosity of the binders.
\end{abstract}

Keywords Rutting performance - Wheel tracking test (WTT) · BS 598-110 · EN 12697-22 small size device

\section{Introduction}

The performance test has become a common way to evaluate asphalt mixture behaviour and a tool to assist in the mixture design. One way to evaluate rutting performance in the laboratory is by performing the wheel tracking test (WTT). Different types of devices were developed to carry out this test under the principle of measuring the permanent deformations that occur in the mixture when it is subjected to a loaded wheel. Several researchers such as Williams et al. [10], Zhou et al. [11], Gabet et al. [2] have studied the different WTT devices and how they characterize rutting behaviour.

The Economic European Community has unified the different WTT standards into the EN 12697-22 standard. Since this standard was developed, many comparative studies between the old and the new WTT standards have been done. Nikolaides and Manthos [6] studied the BS 598-110 and EN 12697-22 small size device methods to observe the sensitivity of each one of them by varying different parameters that affect rutting behaviour.

Perraton et al. [8] carried out a comparative study of WTT results from the small and large size device procedures of EN 12697-22 in order to evaluate their ability to measure rutting performance of bituminous mixtures. This study was also reported by Partl et al. [7].

Garcia Travé et al. [3] compared the WTT test results from the NLT 173 and EN 12697-22 standards 
in AC 16 surf 35/50, one of the mixes most often used in road construction in Europe. The objective was to verify the degree of equivalence or correspondence of the specification limits in both sets of regulations. They found that the limit for the EN 12697-22 small size device given in the PG3 regulation in Spain [9] is more restrictive than the old NLT 173 wheel-tracking test limit. Before the changes of regulations when the $\mathrm{CE}$ marking came into force, all mixes tested in this study met the PG3 requirements and thus were considered apt for use in road construction. However, now these mixes are not in compliance with the regulations.

In Argentina there is vast experience with the WTT according to BS 598-110 and recently, several studies were made with the EN 12697-22 small size device procedure. Nevertheless, there are neither Argentinian standards nor test limits established. Currently the WTT is not a mandatory test, but to characterize the mixture rutting behaviour, the WTT using any of these methods is a specified practice intended to gain experience. Based on the knowledge about the WTT according to BS 598-110 an Rr limit (Agnusdei et al. [1]) has been proposed. These authors found that mixtures with $\mathrm{Rr}<5.2 \mu \mathrm{m} / \mathrm{min}$ in the BS 598-110 WTT present low levels of rutting on pavement roads.

Recently, the Rr limit of Agnusdei et al. was verified considering the rheological properties of the binder such as low shear viscosity (LSV) in Morea et al. [4, 5]. In this work, drastic increases in $\mathrm{Rr}$ were observed when the original bitumen LSV was lower than $500 \mathrm{~Pa} . \mathrm{s}$ at the same temperature as that of the WTT. This LSV limit was approximately related to an $\mathrm{Rr}$ value of $5 \mu \mathrm{m} / \mathrm{min}$ in the BS 598-110 WTT. In addition, Morea et al. [5] studied the variation in BS 598-110 by increasing the load from the standard procedure and related the mixture performance to the binder LSV. They found that, independently of the load level, $5 \mathrm{~mm} / \mathrm{min}$ is the limit at which drastic increases in $\mathrm{Rr}$ are observed.

Taking into account the necessity of a deeper study about acceptable limits for the WTT specified in EN 12697-22 small size device procedure and considering the experience in BS 598-110 WTT, in the present work the WTT performance of several types of mixtures under both methods was studied. The different performance tests were used to analyse and compare the results as well as the calculated parameters in each standard. In addition, this study would serve as a tool for future Argentinian WTT specifications.

\section{Experimental}

\subsection{Mixtures and testing program}

Different types of asphalt mixtures were studied: dense-grade mixtures (coarse and fine), semi-dense mixtures, M10 and stone mastic asphalts (SMA). These mixtures cover a wide range of grades used as surf mixture in Argentinian roads. In addition, they are made with different types of binders; conventional binders (different viscosity grades) as well as polymer modified binders (EVA and SBS). Considering the current trends in asphalt mixtures, some warm asphalt mixtures (WAM) made with warm conventional binders (based on tensoactive additives) were analysed. The characteristics of the different binders and mixtures are listed in Tables 1 and 2, respectively. According to the Argentinian specification, M10 is an open grade mixture. It is similar to SMA without fibres and low bitumen content (5.1-5.3\%). The M10 forms a macro-texture surface and is commonly used on the top surface of pavements to offer better condition to traffic.

For each mixture, slabs $(300 \times 300 \times 50 \mathrm{~mm})$ were made to be tested for performance in the WTT. They were compacted at prefixed densities (variable for each type of mixture) in a roller compactor device according to EN 12697-33. The sample densities were checked before the test.

The performances in the WTT of selected mixtures were evaluated at different temperatures in a range of $50-70{ }^{\circ} \mathrm{C}$. Table 2 shows the temperatures at which the mixtures were tested.

In order to achieve further results, some mixtures (M1, M2 and M11) were compacted at different levels to obtain different air void contents.

The different variables gave a total of 31 case studies in which the performance in the WTT was evaluated according to BS 598-110 and EN 12697-22 small size device procedures.

\subsubsection{Wheel tracking test (WTT)}

The WTT was used to characterize asphalt mixture rutting performance in the laboratory. The wheel- 
Table 1 Main characteristics of the binders

\begin{tabular}{|c|c|c|c|c|c|}
\hline \multicolumn{2}{|l|}{ Asphalt binders } & \multirow{2}{*}{$\begin{array}{l}\text { Penetration } \\
\text { at } 25^{\circ} \mathrm{C}(\mathrm{dmm})\end{array}$} & \multirow{2}{*}{$\begin{array}{l}\text { Viscosity } \\
\text { at } 60{ }^{\circ} \mathrm{C} \text { (Pa.s) }\end{array}$} & \multirow{2}{*}{$\begin{array}{l}\text { Softening } \\
\text { point }\left({ }^{\circ} \mathrm{C}\right)\end{array}$} & \multirow{2}{*}{$\begin{array}{l}\text { Torsional } \\
\text { recovery }(\%)\end{array}$} \\
\hline Argentinian standard & European standard & & & & \\
\hline CA10a & $70 / 100$ & 77 & 211.0 & - & - \\
\hline CA30a & $30 / 50$ & 47 & 418.0 & - & - \\
\hline CA30b & $50 / 60$ & 55 & 316.0 & $-{ }^{*}$ & - \\
\hline $\mathrm{AM} 2 \mathrm{a}$ & PmB(EVA) & 57 & - & 73.0 & 52.2 \\
\hline AM3a & $\operatorname{PmB}(\mathrm{SBS})$ & 66 & - & 80.1 & 84.0 \\
\hline AM3b & $\operatorname{PmB}(\mathrm{SBS})$ & 66 & - & 70.9 & 75.0 \\
\hline $\mathrm{AM} 3 \mathrm{c}$ & $\operatorname{PmB}(\mathrm{SBS})$ & 66 & - & 69.5 & 86.7 \\
\hline $\mathrm{AM} 2 \mathrm{~b}$ & $\mathrm{PmB}(\mathrm{EVA})$ & 64 & - & 69.2 & 67.2 \\
\hline AM3d & $\operatorname{PmB}(\mathrm{SBS})$ & 49 & - & 77.6 & 65.5 \\
\hline $\mathrm{AM} 3 \mathrm{e}$ & $\operatorname{PmB}(\mathrm{SBS})$ & 65 & - & 83.5 & 77.2 \\
\hline AM3f & $\operatorname{PmB}(\mathrm{SBS})$ & 56 & - & 76.0 & 72.0 \\
\hline CA30c & $50 / 60$ & 54 & 338.0 & 52.4 & - \\
\hline CA30d & $50 / 60$ & 55 & 316.0 & $-*$ & - \\
\hline CA30W0 & $50 / 60$ & 53 & 293.0 & 52.6 & - \\
\hline CA30W1 & $30 / 50$ & 49 & 323.5 & 57.0 & - \\
\hline CA30W2 & $50 / 60$ & 57 & 268.0 & 50.6 & - \\
\hline
\end{tabular}

CAXX, different viscosity grade of conventional asphalt; CA10, in Argentinian standard; asphalt with 800-1,600 dPa.s of viscosity at $60{ }^{\circ} \mathrm{C}$; CA30: in Argentinian standard; asphalt with 2,400-3,600 dPa.s of viscosity at $60{ }^{\circ} \mathrm{C}$; AM2 and AM3, most common grade types of Argentinian Modified asphalt Binders; CA30W0, CA30 conventional binder without warm additive; CA30W1 and CA30W2, CA30 Conventional binders with warm tensoactive additives

* Without data

tracking device was placed in a chamber to allow maintaining the sample at the different test temperatures required. This equipment allows to be configured according to BS 598-110 and EN 12697-22 small size device procedures.

Both test methods have similar characteristics. A loaded solid rubber wheel was put over the mixture sample. The sample was placed on a plate capable executing a simple harmonic motion (backward and forward) under the wheel. The wheel travelled a distance of $230 \mathrm{~mm}$ over the mixture. A weighted cantilever arm was used to apply load to the wheel. BS 598-110 and EN 12697-22 standards, however, specify different loads, test times, calculated parameters, frequencies for the simple harmonic motion and wheels (see Table 2). The specified wheel is 200-205 $\mathrm{mm}$ in diameter and $50 \pm 5 \mathrm{~mm}$ wide in both standards, but with different rubber thickness, $10 \mathrm{~mm}$ for BS 598-110 and $20 \mathrm{~mm}$ for EN 12697-22. Figure 1 shows the wheel-tracking device as well as details of loads and wheels.
The test temperature represents the high pavement temperatures. BS 598-110 specifies a test temperature of 45 or $60{ }^{\circ} \mathrm{C}$. EN $12697-22$ is based on the EN 13108-20 standard, which allows the choice of the test temperature according to the high temperature of the pavement where the mixture will be placed. In this work most of the mixtures were tested at $60{ }^{\circ} \mathrm{C}$. Some mixtures were studied at two or three temperatures (50 and 60,60 and 70 or 50,60 and $70{ }^{\circ} \mathrm{C}$ ) to obtain different results, see Table 2.

The rut depth was measured on the sample at $1 \mathrm{~min}$ intervals with a linear variable differential transformer (LVDT). BS 598-110 specifies a single measurement at the centre of the sample, while in EN 12697-22 each rut data point is the average of 25 measurements on the central $100 \mathrm{~mm}$ of the sample wheel path.

The collected data were used to obtain the permanent deformation-wheel pass curves and fitted with the potential model, Eq. 1. Independently of the test procedure, the first ten data points collected were not taken into account because they significantly affect the 
Table 2 Main characteristics of the mixtures

\begin{tabular}{|c|c|c|c|c|c|c|c|c|}
\hline & \multirow[t]{2}{*}{ Mixture type } & \multirow[t]{2}{*}{ Binder type } & \multirow{2}{*}{$\begin{array}{l}\text { Binder } \\
\text { content }(\%)\end{array}$} & \multirow[t]{2}{*}{ Voids (\%) } & \multirow{2}{*}{$\begin{array}{l}\text { Density } \\
\left(\mathrm{g} / \mathrm{cm}^{3}\right)\end{array}$} & \multicolumn{3}{|c|}{ Temperature of WTT $\left({ }^{\circ} \mathrm{C}\right)$} \\
\hline & & & & & & 50 & 60 & 70 \\
\hline & & & & 2.0 & 2.416 & & $\mathrm{x}$ & \\
\hline \multirow[t]{3}{*}{ M1 } & Coarse dense- 1 & CA10a & 5.0 & 4.0 & 2.399 & $\mathrm{x}$ & $\mathrm{x}$ & \\
\hline & & & & 6.0 & 2.358 & & $\mathrm{x}$ & \\
\hline & & & & 2.0 & 2.448 & & $\mathrm{x}$ & \\
\hline \multirow[t]{2}{*}{ M2 } & Coarse dense- 1 & CA30a & 5.0 & 4.0 & 2.400 & $\mathrm{x}$ & $\mathrm{x}$ & $\mathrm{x}$ \\
\hline & & & & 6.0 & 2.350 & & $\mathrm{x}$ & \\
\hline M3 & Fine dense- 1 & CA10a & 4.5 & 4.0 & 2.403 & $\mathrm{x}$ & $\mathrm{x}$ & \\
\hline M4 & Fine dense-1 & CA30a & 4.5 & 4.0 & 2.410 & & $\mathrm{x}$ & $\mathrm{x}$ \\
\hline M5 & semi dense-1 & $\mathrm{CA} 30 \mathrm{~b}$ & 4.5 & 4.0 & 2.420 & & $\mathrm{x}$ & \\
\hline M6 & Coarse dense- 2 & AM2a & 5.0 & 4.1 & 2.423 & & $\mathrm{x}$ & \\
\hline M7 & Coarse dense- 2 & AM3a & 5.0 & 3.5 & 2.423 & & $\mathrm{x}$ & \\
\hline M8 & Coarse dense- 2 & AM3b & 5.0 & 3.9 & 2.423 & & $\mathrm{x}$ & \\
\hline M9 & Semi dense- 2 & AM3c & 4.7 & 4.2 & 2.451 & & $\mathrm{x}$ & \\
\hline \multirow[t]{2}{*}{ M10 } & M10 & $\mathrm{AM} 2 \mathrm{~b}$ & 5.3 & 4.9 & 2.384 & & $\mathrm{x}$ & \\
\hline & & & & 2.0 & 2.424 & & $\mathrm{x}$ & \\
\hline \multirow[t]{2}{*}{ M11 } & M10 & AM3d & 5.3 & 4.9 & 2.384 & & $\mathrm{x}$ & $\mathrm{x}$ \\
\hline & & & & 6.3 & 2.353 & & $\mathrm{x}$ & \\
\hline M12 & SMA & AM3e & 6.0 & 3.3 & 2.376 & & $\mathrm{x}$ & $\mathrm{x}$ \\
\hline M13 & Coarse Dense-3 & AM3f & 5.4 & 4.3 & 2.318 & & $\mathrm{x}$ & \\
\hline M14 & Coarse dense- 4 & CA30c & 4.7 & 2.9 & 2.473 & & $\mathrm{x}$ & \\
\hline M15 & Coarse dense- 5 & CA30d & 5.0 & 2.5 & 2.468 & & $\mathrm{x}$ & \\
\hline M16 & WAM & CA30W0 & 5.0 & 3.0 & 2.422 & & $\mathrm{x}$ & \\
\hline M17 & WAM & CA30W1 & 5.0 & 3.0 & 2.422 & & $\mathrm{x}$ & \\
\hline M18 & WAM & CA30W2 & 5.0 & 3.0 & 2.422 & & $\mathrm{x}$ & \\
\hline
\end{tabular}

SMA stone mastic asphalt mixture, WAM warm asphalt mixture

fit. In this first part, the deformations in the mixture are not related to the shear resistance under study here. The initial settlement is highly dependent on the test conditions (temperature, cycle frequency and load).

$\varepsilon_{\mathrm{p}}=a \cdot N^{b}$,

where $\varepsilon_{\mathrm{p}}$ permanent deformation data; $N$ wheel passes; $a$ and $b$ model constants.

In Europe the proportional rut depth (PRD) is taken as the WTT result, see Table 3. However, this parameter is affected by the initial deformation of the mixture at the beginning of the test. This period is characterized by changes in volume and does not depend on the shear resistance of the mixture. In addition, PRD represents a single value at the end of the test. On the other hand, $\mathrm{Rr}$ and WTS are calculated from a period of time that represents the shear resistance behaviour of the mixture against rutting. Consequently, these parameters are considered a better characterization of the rutting performance of mixtures.

\section{Results and discussion}

The WTT evaluates the permanent deformation of a mixture independently of the standard used (BS 598-110 or EN 12697-22 small size device procedure). The different test configurations (loads, test times and calculated parameters) show the same behaviour with slight differences. A comparative analysis of WTT performances in several mixtures tested with both methods allowed a correlation between criterion and results.

Figure 2 shows the rutting response of mixture M2 tested by both methods. Deformations in the M2 are 

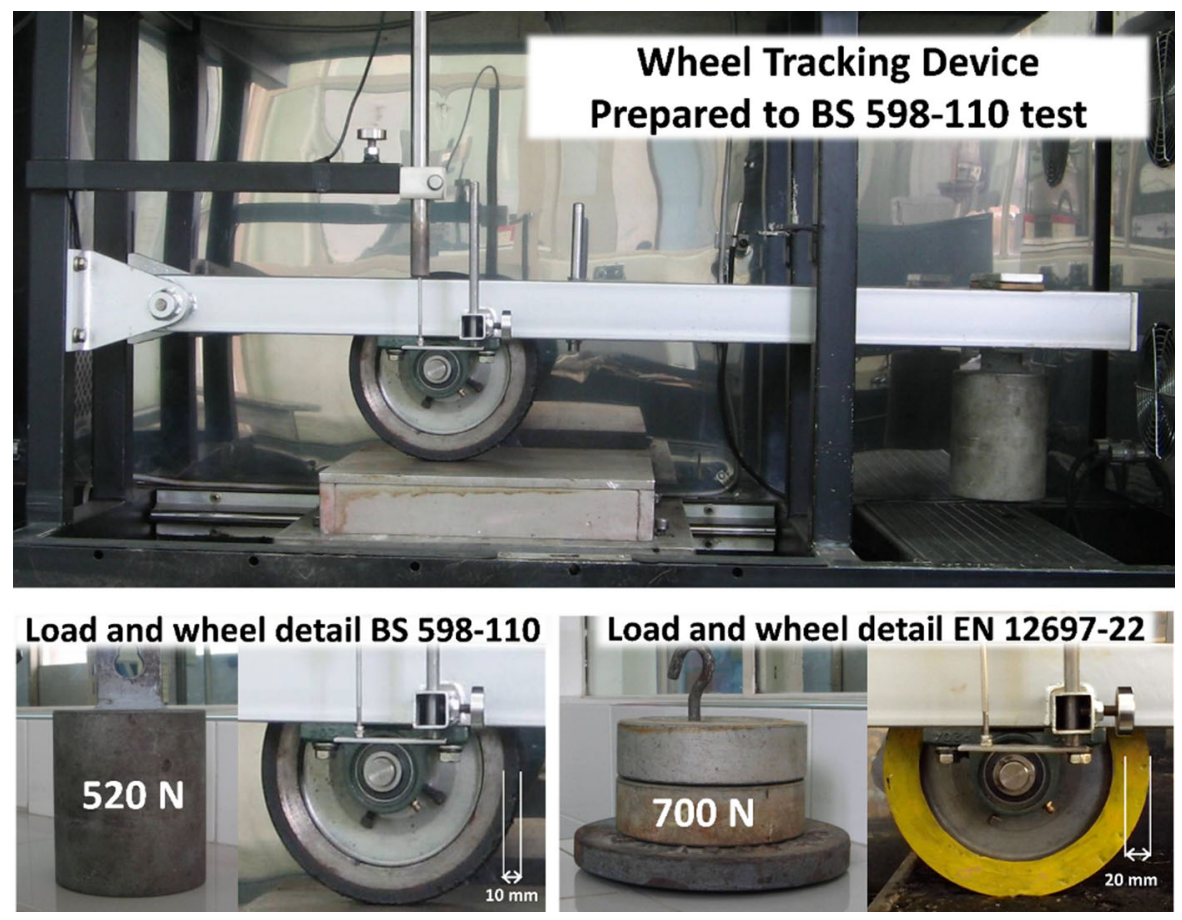

Fig. 1 Wheel tracking device

Table 3 Different characteristics of the WTT methods used

\begin{tabular}{lll}
\hline & BS 598-110 & CEN 12697-22 \\
\hline Load $(\mathrm{N})$ & 520 & 700 \\
Test time (h) & 2 & 6.5 \\
Load frequency (cycles/min) & 21 & 26.5 \\
Calculated parameters & Rutting rate: $\mathrm{Rr}=\frac{\varepsilon_{120}-\varepsilon_{105}}{15 \mathrm{~min}}\left[\frac{\mu \mathrm{m}}{\mathrm{min}}\right]$ & Wheel tracking slope: WTS $=\frac{\varepsilon_{10000}-\varepsilon_{5000}}{5}\left[\frac{\mathrm{mm}}{10^{3} \mathrm{cycles}}\right]$ \\
& & Proportional rut depth: PRd $=\frac{\varepsilon_{10000}}{\text { sampleheight }}[\%]$ \\
Wheel & Diameter: $200-205 \mathrm{~mm}$ & Diameter: $200-205 \mathrm{~mm}$ \\
& Wide: $50 \pm 5 \mathrm{~mm}$ & Wide: $50 \pm 5 \mathrm{~mm}$ \\
& Rubber thickness: $10 \mathrm{~mm}$ & Rubber thickness: $20 \mathrm{~mm}$ \\
\hline
\end{tabular}

$\varepsilon_{120}$ and $\varepsilon_{105}:$ deformations at 120 and $105 \mathrm{~min}$

$\varepsilon_{10000}$ and $\varepsilon_{5000}$ : deformations at 10,000 and 5,000 load cycles

higher with EN 12697-22 than with BS 598-110, as expected because of the higher load. However, the strain rate was similar for both test methods. This is because both tests are very similar and consequently, the rutting resistance will be similar. If a much higher stress level was applied, as in the French wheel tracking test, the rutting rates would be different but, however, there should be a relation between them. In this study, mixture rutting response results are comparable in both test standards considered if the strain rate is taken into account. In conclusion, the strain rate seems to be an effective parameter to characterize the mixture rutting resistance.

In the different mixtures and variations studied it was observed, as in M2 mixture in Fig. 2, that the mixture strain rates for both test methods were similar. Figure 3 shows other mixtures results as example. 
The strain rate is represented by the parameter $b$ in the adjustment model selected to fit the data, see Eq. 1. Figure 4 shows the relation between the b parameters

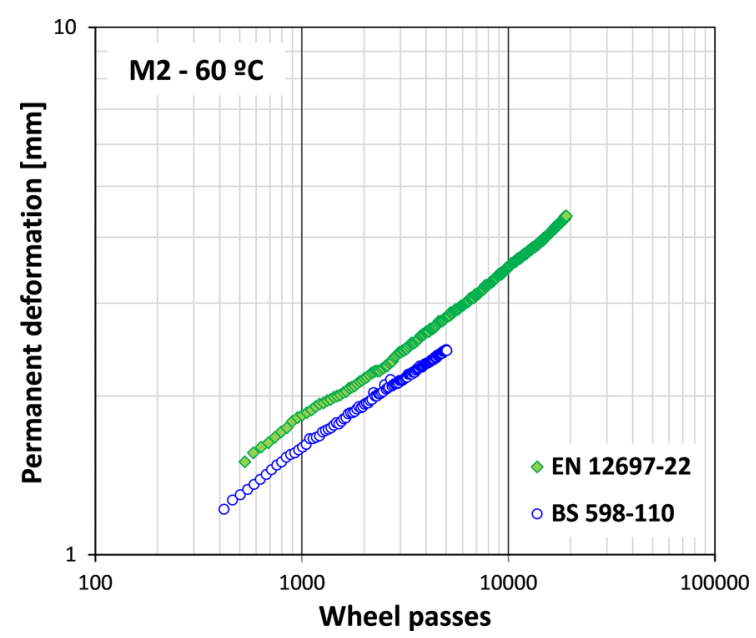

Fig. 2 Permanent deformation versus wheel passes for mixture M2 obtained for the results of the different mixtures in BS 598-110 and EN 2697-22 tests, respectively. It can be observed how parameter $\mathrm{b}$ is similar in both test procedures (BS 5989-110 and EN 1269-22) for the same mixture. The results are distributed around the equality line with a slight bias to higher values of $b$ in EN 12697-22.

In some mixtures behaviours as seen in Fig. 5 were observed. The figure shows how the strain rate is similar in both procedures until completing BS 598-110 test; then in the final part of EN 12697-22 test the strain rate changes due to faster accumulation of deformations. This fact affects the fit and consequently, parameter $\mathrm{b}$ is higher, which explains the bias observed in Fig. 4. It is important to mention that this phenomenon occurs in a few mixtures in which the change of strain rate was lower. Otherwise, a notable bias would have been observed in Fig. 4. The M5 mixture in Fig. 5 was the one that strongly showed this behaviour. In addition, M5 was one of the most rutted mixtures in the study.
Fig. 3 Permanent deformation versus wheel passes for mixture M7, M10, M13 and M17
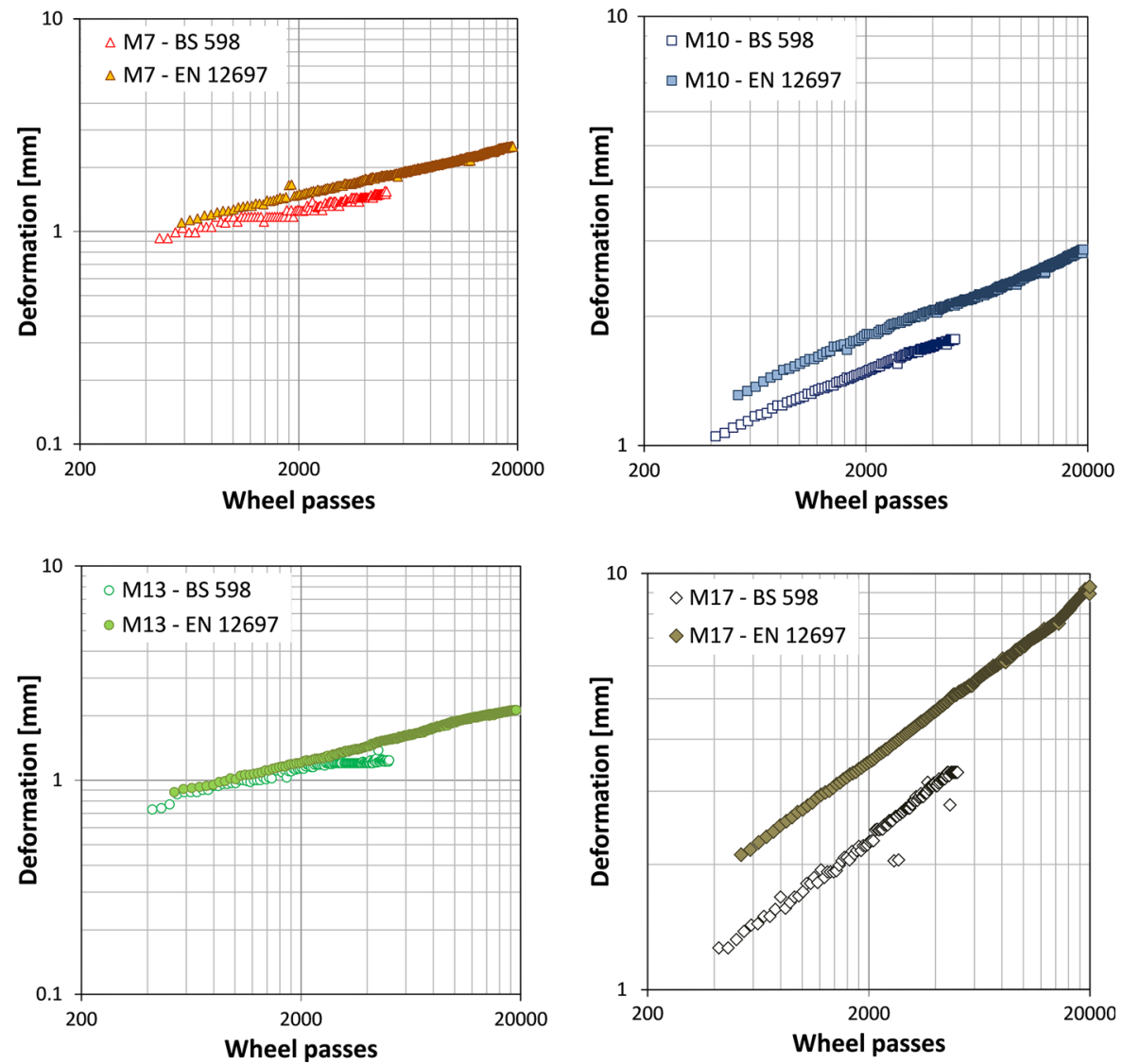


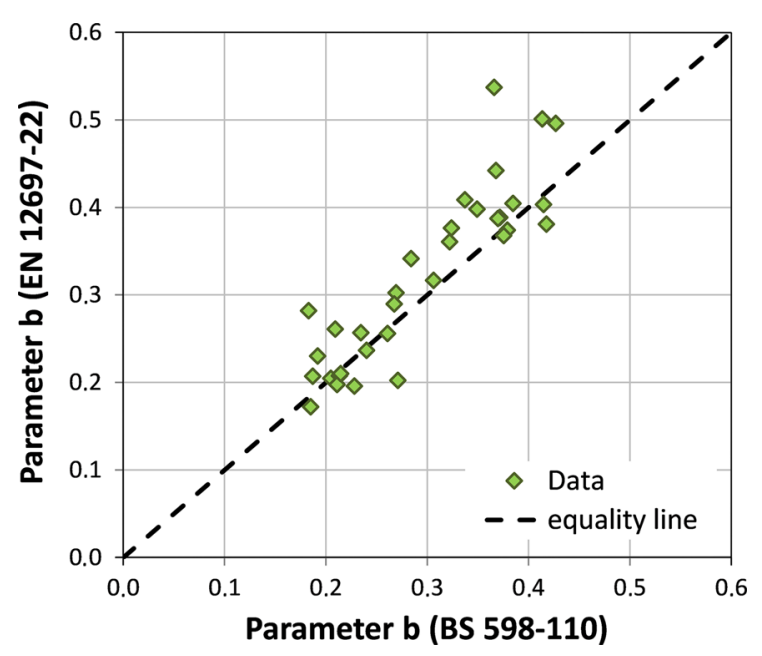

Fig. 4 Relation between $b$ parameters of the mixture studied by both test procedures

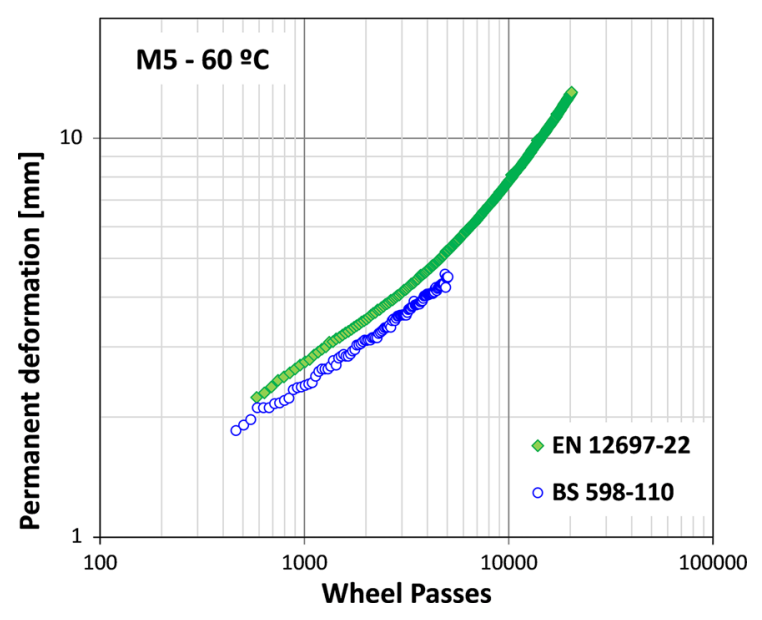

Fig. 5 Permanent deformation versus wheel passes for mixture M5

The change in strain rate could be due to the fact that the mixture is close to reaching what is known as tertiary flow. In this period, the mixture has a high level of rutting predominantly associated with plastic deformations under no volume change conditions. The mixture loses shear resistance and becomes unstable. Since the test time and load of EN 12697-22 are higher than in BS 598-110 this potential behaviour can be observed in these mixtures. Consequently, the EN 12697-22 small size device procedure is more sensible to detect faults in the rutting resistance of mixtures.

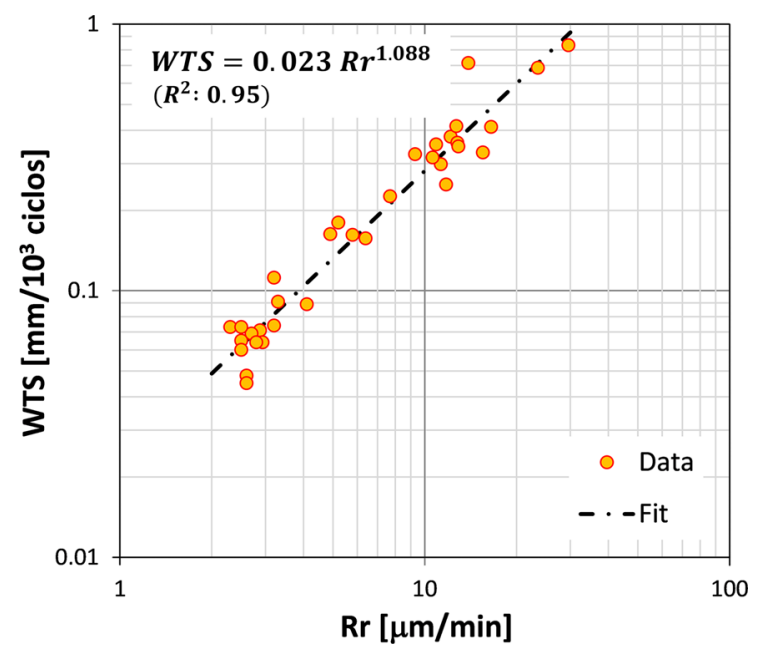

Fig. 6 Relation between WTS and Rr parameters

Parameter $\mathrm{b}$ represents the strain rate in the adjustment model and is analogous to the calculated parameters $\mathrm{Rr}$ and WTS of BS 598-110 and EN 12697-22, respectively. While parameter $b$ is practically the same in both test procedures, Rr and WTS are calculated in different ways. It could be easier to evaluate rutting resistance with parameter $b$; however, $\mathrm{Rr}$ and WTS are extensively used, and experiences and limits related to them have been reported. A correlation between $\mathrm{Rr}$ and WTS would be interesting to compare test results. The Rr and WTS of mixtures studied with the WTT according to BS 598-110 and EN 12697-22, respectively, were calculated. Figure 6 shows the correlation found, which is good, as expected.

In previous work Morea et al. [4, 5], rutting measurements in the WTT (according to BS 598-110) and the LSV of binders have been related. A relation between the mixture Rr and the LSV of the original binder, see Eq. 2, has been proposed in Morea et al. [4]. In this relation the LSV is considered at the same temperature as that of the WTT on the mixture. Furthermore, it was found that the mixtures studied showed drastic changes in rutting resistance when the asphalt binder achieved LSV values lower than 500 Pa.s. On the other hand, Morea et al. [5] reported that the $\mathrm{Rr}$ value of $5 \mu \mathrm{m} / \mathrm{min}$ seems to be a turning point for rutting performance. This $\mathrm{Rr}$ threshold is related to the $500 \mathrm{~Pa}$.s of the LSV limit.

Considering the conclusions of Morea et al. and by means of the WTS-Rr relation in Fig. 6, it can be 
Fig. 7 Permanent deformation versus wheel passes-mixtures with different air void contents
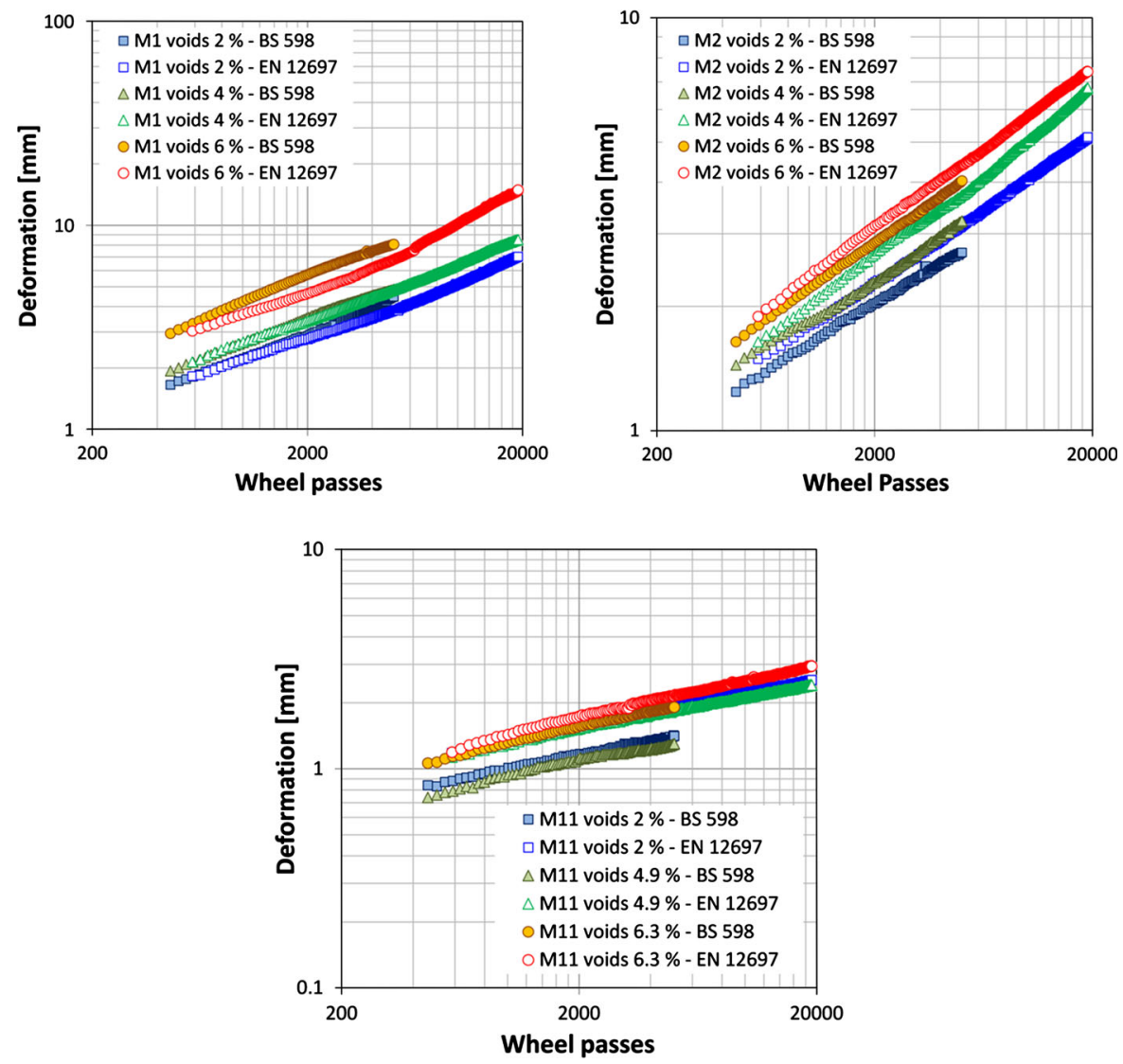

calculated that a $0.132 \mathrm{~mm} / 10^{3}$ cycle of WTS is equivalent to a $5 \mu \mathrm{m} / \mathrm{min}$ of $\mathrm{Rr}$.

$\mathrm{Rr}=1.06+\frac{2287.9}{\mathrm{LSV}_{\text {original }}}$

The PG3 regulation in Spain specifies a WTS of 0.07 or $0.1 \mathrm{~mm} / 10^{3}$ cycles as limits for the WTT in the EN 12697-22 small size device procedure depending on climate conditions and transit level.Garcia Travé [3] found these limits to be more restrictive than the old NLT 173 wheel-tracking test limits. Considering the limit found in this work, the WTS limits of PG3 are rigorous, especially the $0.07 \mathrm{~mm} / 10^{3}$ cycles limit. Using the relation WTS-Rr and Eq. 2, it was possible to infer that the $0.07 \mathrm{~mm} / 10^{3}$ cycles of WTS are related to a high binder LSV of 1315 Pa.s. This LSV value is bigger than the value of $500 \mathrm{~Pa}$.s proposed by Morea et al. [4]. This binder viscosity is obtained in polymer modified binders or at low temperatures, limiting the types of mixture that can be used in normal conditions where rutting appears.
Some mixtures (M1, M2 and M11) were compacted at different levels to obtain different air void contents and evaluate WTT performance. Also, the mixtures M1, M2 and M11 with the designed air voids plus M3, M4 and M12 were evaluated in the WTT at different temperatures to observe their behaviour.

Figure 7 shows the WTT results for M1, M2 and M11 with different air void contents. Higher deformations occur as the air void contents increase. This is because the higher the initial air void content is, the higher the initial deformation results. However, the rutting rate is similar independently of the air void content, at least for the mixtures studied in the present work.

Figure 8 shows the WTT result for M1, M2, M3, M4, M11 and M12 at different temperatures. In the figure can be observed higher deformations and strain rate increase as the temperature rises, as expected. In the mixture M4 tested at $70{ }^{\circ} \mathrm{C}$ it can be observed a similar behaviour like was described for mixture M5, see Fig. 5. 
Fig. 8 Permanent deformation versus wheel passes-mixtures tested at different temperatures
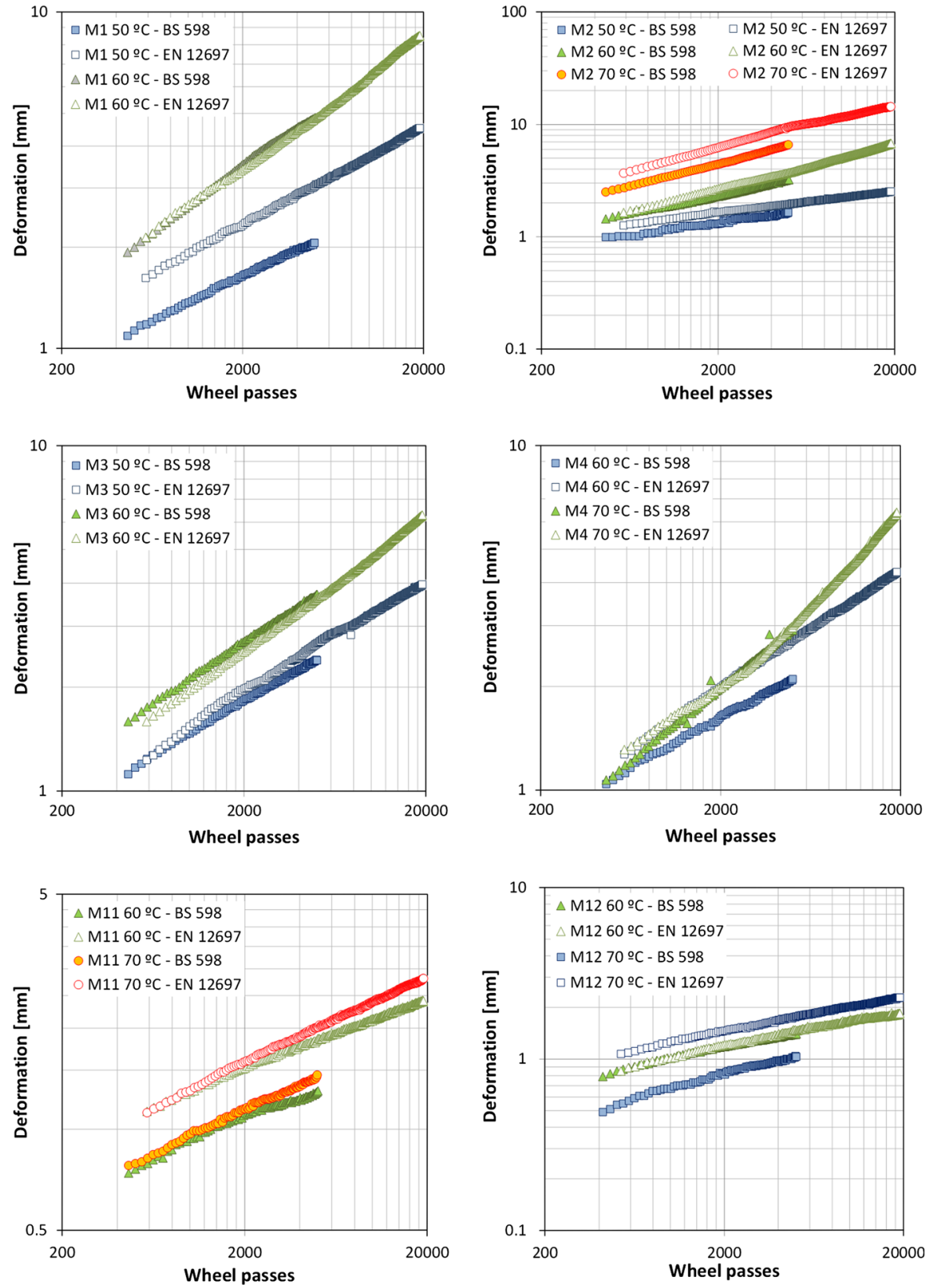

\section{Conclusions}

In this work two WTT standards (BS 598-110 and EN 12697-22 small size device procedures) were comparatively studied. The performance of several types of mixtures with different binders and test conditions were evaluated in the WTT with both test methods. The main conclusions are as follows.
The rutting resistance of the studied mixtures is characterized in a similar way by both test methods (BS 598-110 and CE 12697-22 small size device procedures) when the strain rate of test results is considered.

The calculated parameters Rr of BS 598-110 and WTS of EN 12697-22 were correlated and are represented by the following equation: 
WTS $=0.023 \mathrm{Rr}^{1.088}$.

This correlation allows the comparison of results of performance tests under these methods and can be used as a tool for new research as well as database for the future Argentinian standard for the WTT.

It was observed that certain European limits of WTS could be rigorous and must be further studied.

Acknowledgments The authors wish to thank the collaboration of Eng. Rosana Marcozzi, Claudio Veloso, Jorge Coacci, Norberto Amarillo and Javier Batic during the experimental work.

\section{References}

1. Agnusdei J, Iosco O, Jair M, Morea F (2007) Correlación entre medidas de Ahuellamiento in situ y ensayos de laboratorio $2^{\mathrm{a}}$ parte. XIV Congreso Ibero Americano del Asfalto

2. Gabet T, Di Benedetto H, Perraton D, De Visscher J, Gallet T, Bankowski W, Olard F, Grenfell J, Bodin D, Sauzéat C (2011) French wheel tracking test round robin test on a polymer modified bitumen mixture. RILEM TC 206-ATB, TG3: mechanical testing of mixtures. Mater Struct 44:1031-1046. doi:10.1617/s11527-011-9733-X

3. García-Travé G, Martinez-Echevarria MJ, Rubio Gámez M (2012) Bituminous mix response to plastic deformations: comparison of the Spanish NLT-173 and UNE-EN 12697-22 wheel tracking tests. Dyna 174:51-57. ISSN 0012-7353
4. Morea F, Zerbino R, Agnusdei J (2013) Improvements on asphalt mixtures rutting performance characterization by the use of low shear viscosity. Mater Struct 46:267-276

5. Morea F, Zerbino R, Agnusdei J (2013b) Wheel tracking rutting performance estimation based on bitumen low shear viscosity (LSV), loading and temperature conditions. Mater Struct. doi:10.1617/s11527-013-0088-3

6. Nikolaides A, Manthos E (2009) The effect of volumetric properties of asphalt concrete mixture to wheel track rutting with respect to EN and BS rutting test method. In: Proceedings of 7th International RILEM symposium ATCBM09 on Advance testing and characterization of bituminous materials, vol II, pp 1019-1028

7. Partl MN, Bahia H, Canestrari F, De la Roche C, Di Benedetto H, Piber H, Sybilski D (2013) Advances in interlaboratory testing and evaluation of bituminous materials. State-of-the-art reports of the RILEM TC 206-ATB. ISBN: 978-94-007-5103-3 (Print) 978-94-007-5104-0 (Online), doi:10.1007/978-94-007-5104-0, pp 453

8. Perraton D, Di Benedetto H, Sauzéat C, De La Roche C, Bankowski W, Partl M, Grenfell J (2011) Rutting of bituminous mixtures: wheel tracking test campaign analysis. Mater Struct 44:969-986

9. Pliego de Prescripciones Técnicas Generales para Obras de Carreteras y Puentes (PG-3) (2004) $4^{\mathrm{a}}$ Edición. Ediciones Liteam

10. Williams RC, Prowell BD (1999) Comparison of laboratory wheel-tracking test results with westrack performance. Transportation Research Record 1681 99-1457:121-128

11. Zhou F, Chen Dar-Hao, Scullion T, Bilyeu J (2003) Case study: evaluation of laboratory test methods to characterize permanent deformation properties of asphalt mixes. Int $\mathbf{J}$ Pavement Eng 4(3):155-164 